\title{
DARWIN: DE DÓNDE Y ADÓNDE. ANTECEDENTES Y CONSECUENCIAS DEL PENSAMIENTO EVOLUCIONISTA
}

\section{DARWIN: WHERE FROM AND WHERE TO. PROLEGOMENA AND CONSEQUENCES OF EVOLUTIONARY THOUGHT}

\author{
Vicente Claramonte SANZ \\ Departamento de Lógica y Filosofía de la Ciencia \\ Universidad de Valencia
}

RESUMEN: El artículo sugiere ciertas reflexiones sobre los principales antecedentes y consecuencias de la obra de Darwin, desde la perspectiva de su impacto en la cosmovisión de la sociedad. Desarrolla cómo el pensamiento darwinista supuso, en el área de conocimiento cubierta por la Biología, el transcurso del mito al logos, de una filosofía biológica atemporal a la integración de la vida en el tiempo geológico y cosmológico, y del determinismo característico de la mecánica clásica newtoniana al indeterminismo propio del paradigma cuántico-evolucionista.

PAlabRas ClaVE: Darwinismo, ontología, epistemología.

ABSTRACT: This paper suggests some reflections about Darwin's work main antecedents and consequences, from de perspective of its impact on society's world view. It developes how darwinist tought meant, in the biological knowledge area, the course from myth to logos, from a timeless biological philosophy to the integration of life in geological and cosmologic time, and from determinism characteristic in classic newtonian mechanics to indeterminism typical in quantum-evolutionist paradigm.

KEYWORDS: Darwinism, ontology, epistemology. 
Durante 2009 se conmemora el bicentenario del natalicio de Charles Robert Darwin en Shrewsbury, capital del Condado de Shropshire en Inglaterra, el 12 de febrero de 1809, y simultáneamente el centésimo quincuagésimo aniversario de la primera edición de El origen de las especies. Esta obra capital explica verosímilmente cómo surgen y se transforman las especies de organismos, mostrando que toda forma de vida conocida desciende de un ancestro común y evoluciona mediante la acción de la selección natural, premisa para afirmar que el ser humano está afectado por los mismos principios biológicos que los restantes seres vivos de la Tierra. Siglo y medio tras publicarse, la comunidad científica sigue acumulando pruebas que confirman sus tesis principales. En general, la obra de Darwin resultó tan subversiva para la ideología dominante en la sociedad de su época, fuertemente influenciada por una cosmovisión religiosa teísta, porque la teoría evolucionista expone, a partir de la evidencia disponible en la naturaleza y de mecanismos causales de índole natural, el itinerario conducente a mostrar, sin recurrir a la causalidad sobrenatural ad hoc postulada por las explicaciones precedentes, la incardinación previa y subsiguiente relación de la especie humana con el resto de organismos y seres vivos integrantes de la biosfera.

Antes de surgir la teoría darwinista, la historia del pensamiento muestra cómo los fenómenos y procesos biológicos fueron casi exclusivamente concebidos desde el creacionismo, y por tanto, objeto de explicaciones mitológicas tejidas en torno a una deidad personificada generadora del cosmos y la vida, ex nibilo o a partir de ciertos elementos abstractos preexistentes. A consecuencia del predominio de las explicaciones teístas, la mediación cosmogónica de un ser sobrenatural omnipotente, entre cuyos atributos exclusivos se contaba la eternidad, impuso cariz atemporal a la Filosofía de la Biología, extrayéndola fuera de todo tiempo histórico observable. Por lo demás, durante el siglo XVIII, época en que se formaron casi todos los intelectuales influyentes en la obra de Darwin, la ciencia impulsada por la Ilustración tal vez logró sus más altas cotas de desarrollo teórico con la elaboración de la mecánica clásica, caracterizada entre otros rasgos por el determinismo.

La irrupción del genial pensamiento de Darwin alteró radicalmente ese escenario ideológico. El surgimiento de su figura histórica supone, en el contexto de la sociedad occidental coetánea, una comunidad científica con conocimiento y madurez suficiente para argumentar, en ciencias biológicas, el tránsito del creacionismo al evolucionismo, de la atemporalidad a la temporalidad y del deter- 
minismo al indeterminismo. El origen de las especies impulsó una auténtica revolución del paradigma explicativo en Biología, justificando el transcurso del mythos creacionista al logos evolucionista mediante una teoría que, frente a la atemporalidad característica de una deidad creadora eterna, integraba la vida y la diversidad de las especies en la dinámica del tiempo geológico, y frente al determinismo propio del modelo seguido por la física mecanicista imperante, permitió incorporar el azar al estudio de los fenómenos naturales relativos a la vida.

Pero veamos con cierto detalle algunos apuntes y reflexiones, acerca del papel desempeñado por el pensamiento evolucionista de Darwin como agente sinérgico en la transición de las continuidades y discontinuidades entre cosmovisiones tan excluyentes como fijismo y evolucionismo.

\section{Del creacionismo al evolucionismo: transcurso del mythos al logos y revolución del paradigma explicativo}

La comprensión de la naturaleza desde una perspectiva evolucionista, como es sabido, surgió en la historia del pensamiento de la humanidad muchos siglos antes del nacimiento de Charles Darwin, quien no fue el primer pensador evolucionista, sino más bien el primero en elaborar una teoría sobre la evolución calificable como científica. Pero hasta la publicación de El origen en 1859, el pensamiento evolucionista apenas si era testimonial entre el paradigma creacionista dominante, tanto en la cultura occidental como en otras, y de hecho siguió siendo minoritario durante casi todo el siglo posterior. Ahora bien, no obstante ser hasta entonces el creacionismo la norma y el evolucionismo la excepción, sí podrían engrosar los anales de la filosofía biológica ciertos precedentes de ideas evolucionistas, de cuya curiosa singularidad nos resistimos a privar al paciente lector.

En la antigua Grecia, varios filósofos presocráticos ya plantearon ideas de índole evolucionista respecto al origen de los seres vivos. Entre ellos, destacan Anaximandro de Mileto (circa 610-545 a.C.), Heráclito de Éfeso (circa 544-484 a.C.) y Empédocles de Acragante (circa 494-434 a.C.).

En cuanto a Anaximandro, los testimonios indican que trató de explicar el origen de los seres vivos de modo racional, no sobrenatural, y entrevió la noción 
de evolución biológica. Al afirmar que los primeros animales surgieron en un medio acuoso y luego se desplazaron a otro terrestre, de algún modo sostuvo implícitamente que las especies animales proceden de otras anteriores y diferentes, y por tanto constituyen el producto de una transformación evolutiva ${ }^{1}$. Además, observando la desproporción existente entre la fase de cría del ser humano y la de otros animales, infirió el surgimiento de la especie humana a partir de especies ancestrales ${ }^{2}$. Es decir, recurrió a la idea de transformación de las especies para explicar cómo el ser humano pudo superar las dificultades que para su supervivencia suponía atravesar etapas de amamantamiento, cría y educación más prolongadas que otros animales, con la consiguiente mayor exposición al riesgo de sucumbir, derivada de una más perdurable incapacidad para la autoconservación ${ }^{3}$.

Heráclito constituye el primer precedente histórico explícito de una concepción dinámica y evolutiva de lo real, al afirmar que todo fluye y se desarrolla continuamente: «A quienes se introducen en los mismos rios, nuevas aguas les afluyen una y otra vez» ${ }^{4}$. Fragmento éste habitualmente citado con otra formulación, más conocida y a la vez considerada por muchos expertos como una versión libre de la anterior, según la célebre sentencia «No es posible introducirse dos veces en el mismo rio» ${ }^{5}$. Platón (428-348 a.C.) explica el sentido de temporalidad, movimiento, cambio y evolución inherente a esta cosmovisión, tan distinta de la suya,

1 «Anaximandro dice que los primeros animales nacieron en lo húmedo, envueltos en cortezas espinosas, y que cuando llegaron a una edad más avanzada se trasladaron a lo más seco, y al desgarrarse la corteza sobrevivieron durante poco tiempo». Aecio V, 19, 4.

2 "Dice además [Anaximandro] que el hombre, originariamente, surgió de animales de otras especies, porque las demás especies se alimentan pronto por si mismas, y sólo el hombre necesita de un largo período de crianza. Por ello, si originariamente hubiera sido como es [ahora], no hubiera podido sobrevivin. Ps. Plutarco, Strom., 2 (D-K 12 A 10).

3 Véase por ejemplo, Censorino, 4, 7: "Anaximandro de Mileto pensaba que del agua y de la tierra calentadas nacieron peces o animales muy semejantes a los peces, y que dentro de ellos se formaron los hombres, siendo retenidos los fetos en su interior hasta la pubertad; fue entonces cuando se rompieron aquéllos y aparecieron hombres y mujeres que ya podian alimentarse por sí mismos». O también Plutarco, Symp. VIII 8, 4, p. 730 E: "[Anaximandro] no afirma que los peces y los hombres nacieran en las mismas circunstancias, sino que los hombres, en un principio, nacieron y fueron alimentados dentro de peces _ como los escualos_-, y que cuando llegaron a ser capaces de cuidarse por si mismos, emergieron y saltaron a tierra».

4 Ario Dídimo, ap. Eusebio P. E. XV, 20.

5 Plutarco, 18, 392 B. 
basada en lo eterno, inalterable y permanente ${ }^{4}$ : "Dice Heráclito en algún lugar que todo pasa y nada permanece, y, comparando las cosas con la corriente de un rio, dice que no podrías introducirte dos veces en el mismo rio» 7 . La comprensión dinámica y evolutiva se refuerza en el pensamiento heracliteano al elegir entre los elementos agua, aire, fuego y tierra para señalar el arkhé, o principio explicativo del mundo: "Este mundo, el mismo de todos, no lo hizo ninguno de los dioses ni de los hombres, sino que siempre fue, es y será fuego siempre vivo que se enciende según medidas y se extingue según medidas» ${ }^{8}$. Esto es, como razón última para comprender y explicar el mundo y la naturaleza, designa al fuego, símbolo filosófico del cambio, de la realidad en constante proceso de transformación evolutiva.

Las consideraciones biogónicas recibidas de Empédocles plantean también una concepción dinámica y transformadora entre las sucesivas generaciones de organismos vivos, añadiendo además una cierta idea de combinación, como causa del mejoramiento de las especies, que recuerda vivamente el vínculo existente entre el azar y la acción de la selección natural ${ }^{9}$. En su filosofía, el origen de los seres vivos se habría producido, a lo largo de cuatro estadios de evolución biogónica, mediante el ensamblaje de miembros y órganos por azar. Este ensamblado aleatorio y sucesivo habría originado múltiples combinaciones, de modo que las más eficaces sustituirían paulatinamente a las ineptas con el transcurso de las generaciones, hasta estabilizarse aquellas combinaciones de miembros que permitieran formar especies de seres vivos capaces de sobrevivir.

También en la cultura tradicional desarrollada en China entre los siglos IV a.C. y I, aparecen indicios de una comprensión evolutiva de la vida y la naturaleza. La filosofía cosmogónica oriental coetánea nunca incluyó la idea de creación abrupta, repentina y ex nihilo, por lo que tampoco desarrolló la idea fijista de inmutabilidad de las especies. De ahí que sus textos reflejen la observación de

${ }^{6}$ Y por ello mismo, una de las principales fuentes del creacionismo occidental.

7 Platón, Crátilo, 402 a.

8 Clemente, Strom. V, 105.

${ }^{9}$ "Dice Empédocles que las primeras generaciones de animales y vegetales no nacieron completas, sino desunidas en partes incompatibles; las segundas, cuyas partes estaban combinadas, eran como los seres de la fantasía; las terceras eran de seres de naturaleza completa; las cuartas no procedian ya de los semejantes como la tierra y el agua, sino unas de otras, [...] Y las razas de todos los animales se diversificaron de acuerdo con la cualidad de sus mezclas». Aecio, V, 19, 5 (D-K 31 A 72): Eggers, 1986: pp. 89-92. 
las graduales transformaciones de los seres vivos en el tiempo ${ }^{10}$, admitiendo la posibilidad de acumular paulatinas modificaciones en un resultado final conducente a la evolución. En la obra Chiang Tzu, del siglo IV a.C., consta expresamente la idea de transformación evolutiva, así como la comprensión del cambio biológico como fruto de la adaptación a un entorno específico. E incluso podría rastrearse, en aquellos de sus pasajes que señalan las «ventajas de ser inútil» que la presa brinda a los depredadores ${ }^{11}$, un precedente de la noción de selección natural. En el siglo I de nuestra era, surgió además el gran pensador Wang Chung. Cual ilustrado europeo del siglo XVIII intentando mitigar oscurantistas lacras medievales, se rebeló contra la esclerosis social producida por el confucianismo imperante, apelando a la experiencia y a la razón crítica para combatir los mitos, falsas creencias y supersticiones elaboradas secularmente al socaire de la filosofía tradicional china. Su libro, titulado Lun Hêng (circa 83), defiende con nitidez la posibilidad de explicar toda transformación biológica por causas naturales y sin recurrir a discursos mitológicos, emplea nociones próximas a las ideas de herencia genética, mutación, migración animal o tropismo, y presupone una integración plena del ser humano en el reino animal, sin reservarle un compartimento estanco al margen o un estatus privilegiado superior. Mutatis mutandis, estaríamos por tanto ante el Darwin o, al menos, el Lamarck oriental del siglo I.

Pero distingamos la anécdota de la categoría. Como se indicó, estos precedentes de pensamiento evolucionista constituyeron casos excepcionales, hasta la irrupción de la teoría científica evolutiva propuesta en El origen. Exceptuando algunas aportaciones de Lamarck (1744-1829), desde la singularidad histórica de los anecdóticos precedentes descritos hasta Darwin, hubo poco más. Antes la norma era el creacionismo, es decir, la explicación mítica de los fenómenos biológicos a partir de un Supremo Hacedor, de un ser sobrenatural creador del cosmos y la vida, mientras el evolucionismo fue sólo la excepción. Las tres grandes religiones monoteístas coincidían casi a pies juntillas. En la cultura occidental y hasta la difusión del pensamiento darwinista, la influencia en la superestructura de la sociedad producida por la explicación bíblica de la Creación había consolidado una ideología especulativa, sistematizada y difusora de ciertos principios dogmáticos inatacables. Estos dogmas propiciaron el estancamiento secular del progreso en el conocimiento científico, y concretamente en Biología, contribu-

${ }^{10}$ Needham, J. et al., 1952.

11 Needham, J. et al., 1954: vol. II: pp. 78-81. Citado en Alonso, 1999: p. 16. 
yeron a generalizar un conocimiento sobre los organismos vivos y las especies animales y vegetales pleno de lagunas, confuso e impreciso y falto de descripción, cuantificación y clasificación.

Así ocurrió con el registro fósil, cuyo tratamiento creacionista bloqueó durante siglos el avance del conocimiento científico en ciencias naturales, al ofuscar el estudio de la Paleontología como una disciplina auxiliar, cuyos hallazgos permitirían después a los biólogos establecer y demostrar las inferencias clave sobre las relaciones evolutivas existentes entre especies extintas y organismos vivos. Según la hipótesis explicativa creacionista, mayoritaria en el paradigma científico-biológico precedente a la teoría evolucionista de Darwin y en la sociedad de mediados del siglo XIX, los fósiles no eran considerados como el resto petrificado de organismos otrora vivos, ni la evidencia de especies extinguidas en tiempos remotos. Eran descritos como «quimeras» o «juegos» de la naturaleza formados durante el acaecimiento del Diluvio universal, supuestamente creados por voluntad de Dios como modelos arquetípicos de los organismos vivos, e incluso por la del Diablo para tentar, confundir o aterrorizar a los creyentes. Además, la carga ideológica de la hipótesis creacionista proscribía aceptar la extinción de ciertas especies, fenómeno incompatible con la Creación de la naturaleza como obra perfecta de factura divina. Prejuicio que, salvo excepciones honrosamente científicas, hasta la teoría evolucionista de Darwin bloqueó la predisposición a apoyar con el registro fósil las inferencias básicas sobre procesos evolutivos interespecíficos.

Tres núcleos de cuestiones pueden sintetizar los principales dogmas establecidos por la explicación bíblica de la Creación narrada en el Libro del Génesis. La aceptación generalizada de la cosmogonía y cosmología descritas en las Sagradas Escrituras como axiomas irrefutables, el fijismo definitivo de las especies animales y vegetales, cuya transformación tras la Creación divina resultaba inadmisible, y por último, la brevísima edad del planeta Tierra, cuyo origen fue remontado al año 4004 a.C. por el arzobispo irlandés James Usher. Destacaremos la importancia del dogma sobre la joven Tierra, clave de la bóveda argumentativa creacionista, y su incompatibilidad con la noción de tiempo geológico, de macroperíodo temporal, ingrediente que accede a El origen de las especies a partir de la interiorización de la obra de Charles Lyell (1797-1875) por su admirador y amigo Darwin, tras la lectura de Principios de Geología durante el célebre viaje en el Beagle. Pues esta idea de tiempo geológico, preludio de una cronología cosmo- 
lógica global, constituye la premisa ineludible para asimilar el mecanismo evolutivo que comporta la transformación de las especies.

En 1650, James Usher (1581-1656), profesor de Teología, arzobispo de Armahg y primado de Irlanda, junto a John Lightfoot (1602-1675), doctor por la Universidad de Cambridge, tras ciertos cálculos basados en datos obtenidos a partir de la lectura del Antiguo Testamento, concluyeron que el universo fue creado por Dios ex nibilo a las 9 de la mañana del domingo 23 de octubre del año 4004 a.C. En su obra Annalis Veteris et Novi Testamenti, cuyas dos primeras ediciones datan de 1650 y 1654, Usher afirma además que el martes 25 siguiente las aguas se concentraron en cierto lugar de la Tierra hasta emerger tierra firme, el viernes 28 fue creado el ser humano y el diluvio universal ocurrió 1656 años después, porque Noé abordó el arca el 7 de diciembre de 2349 a.C. y desembarcó el 6 de mayo de 2348 a.C., tras cinco meses menos un día de ardua navegación diluvial y zoófila.

Tras publicarse esta obra, la autoridad eclesiástica católica de la época asumió su datación cosmogónica como históricamente rigurosa, estableciendo a partir de la misma ciertas verdades de fe incuestionables. Según las mismas, el universo, la Tierra y la vida fueron creados por Dios, y el estado actual del cosmos se explica a partir del acto creativo iniciático y de ciertas catástrofes de génesis divina como el Diluvio universal. Además dicha Creación, producida abruptamente conforme al proceso semanal descrito en el Libro del Génesis, acaeció hace unos 6.000 años, aunque revisiones posteriores, también religiosamente inspiradas y continuistas en lo fundamental, retrasan la fecha hasta unos 8.000 años atrás. Esta concepción, conocida como catastrofismo o principio catastrofista, permaneció indiscutida como explicación cosmogónica dominante y sin alternativa plausible hasta publicarse El origen de las especies de Charles Darwin. E incluso todavía perdura, especialmente en los Estados Unidos, entre sectores sociales proclives al fundamentalismo cristiano, ultrarresistentes a retractarse de su creencia y aferrados a la datación de Usher sobre el origen de la Tierra descrito por la Biblia.

Así se explican las sospechas suscitadas por la teoría evolucionista hace ciento cincuenta años en la sociedad coetánea de Darwin. Particularmente en aquellos de sus ambientes más partidarios de la ideología religiosa, así como en los ateneos científicos y entornos sociales, intelectuales o culturales donde miem- 
bros de la jerarquía eclesiástica desempeñaban un rol social de cierta relevancia. Por ejemplo, como es harto conocido, así ocurrió en una memorable sesión de la British Association for de Advancement of Science, acaecida en la Universidad de Oxford el 30 de junio de 1860, apenas un año tras publicarse El origen, cuando polemizaron desabridamente Samuel Wilberforce, arzobispo de la propia ciudad universitaria conocido por su fina e incisiva retórica, y Thomas Henry Huxley, zoólogo apodado el «bulldog de Darwin», por convertirse en el principal adalid de su teoría evolutiva ante la oposición religiosa más acérrima ${ }^{12}$. La reacción de las más altas autoridades de la jerarquía católica, ante la tensión ideológica generada entre el neonato evolucionismo darwinista y la concepción creacionista aún dominante, no tardó en pronunciarse. El sínodo diocesano, celebrado ese mismo año en Colonia, declaró contraventora de la fe y las Sagradas Escrituras toda tesis según la cual el ser humano surgió de un previo estadio natural y no de un acto divino creador. Las conclusiones de dicho sínodo preconcibieron así una doctrina oficial de la iglesia católica contra la evolución, ratificada cuatro años más tarde por Su Santidad el Papa Pío IX, el 8 de diciembre de 1864, con en su encíclica Quanta cura.

Al posicionamiento del catolicismo definido desde la autoridad institucional, subsiguió el de sus líderes intelectuales. Quienes, dadas las circunstancias, consideraron urgente patrocinar ateneos y círculos científicos con impronta religiosa, destinados a articular y divulgar un discurso beligerante contra la teoría evolucionista de Darwin, reputada doctrina errónea y subversiva, concitándose en ellos los científicos católicos con la intención declarada de coadyuvar a refutarla. Fruto de su activismo, pronto se fundaron en diversos países europeos las primeras sociedades científicas de inspiración religiosa. Entre ellas, desde 1875 destacó la Société Scientifique des Bruxelles, cuyo objeto social era reclutar un nutrido batallón cristiano de científicos y clérigos, militante contra el racionalismo y

12 Algunas de cuyas recíprocas intervenciones en dicho debate son perlas ya legendarias, como cuando Wilberforce preguntó a Huxley si le resultaba indiferente proceder del mono, pues según sus palabras: «Si lo que se me pregunta es a quien prefiero como abuelo, si a un miserable simio o un hombre muy bien dotado por la naturaleza y en posesión de grandes recursos e influencia pero que, sin embargo, emplea esas facultades y esa influencia con el único propósito de introducir el ridículo en una importante discusión cientifica, proclamo sin titubear mi preferencia por el simio. A lo que el público respondió con interminables risas, tras las cuales escucharon el resto de mi intervención con suma atención». Citado en Gardner, 1995, pp. 145-6, a partir de Huxley, J. y Kettlewell, H., 1987; e igualmente, con el mismo sentido aunque con un tenor algo diferente, citado en Pelayo, 2001: p. 139. 
el ateísmo con las armas de la «verdadera» ciencia. A través de su órgano de expresión, Revue des Questions Scientifiques, la Société promovió entre 1888 y 1900 la organización de congresos internacionales de científicos católicos con vehementes debates sobre, o más bien anti-evolución.

Estas tensiones entre modelos explicativos opuestos en la comprensión de los fenómenos biológicos, diría Thomas Kuhn (1922-1996), señalan la crisis del paradigma científico precedente, así como el inicio de su desgajamiento y sustitución final por el paradigma emergente posterior. La ciencia compatible con el creacionismo, plagada de anomalías inexplicables desde su propia coherencia teórica interna confrontada con las más simples e inmediatas observaciones, entra definitivamente en crisis ante el surgimiento de un desarrollo teórico que lo reduce en potencia conceptual, explicativa y demostrativa. Más aún, la discontinuidad entre creacionismo y evolucionismo apunta una revolución cognitiva de mayor profundidad que la mera transformación del paradigma científico, pues supone el abandono de una explicación basada en un relato mitológico desprovisto de toda racionalidad demostrable y su sustitución por una teoría articulada a partir de la evidencia empírica y el razonamiento demostrativo.

Por ello, en Biología, la relación entre creacionismo y evolucionismo es análoga a la habida en Epistemología entre mito y razón. Hasta divulgarse la teoría darwinista, los fenómenos biológicos eran comprendidos y explicados mediante concepciones de raigambre creacionista, justificadas en tradiciones religiosas milenarias procedentes de diversas culturas y transmitidas por textos considerados sagrados. Es decir, basadas en explicaciones mitológicas orbitarias en torno a una deidad personificada, sobrenatural y omnipotente. Por el contrario, desde el punto de vista epistemológico, la teoría de la evolución de Darwin supuso en Biología el transcurso del mythos al logos, es decir, el transcurso de una concepción creacionista basada en una explicación de tipo mitológico, a otra evolucionista basada en una explicación de tipo lógico-científico. Transición teórica causante de inevitables tensiones ideológicas como las reseñadas. 


\section{De la atemporalidad a la temporalidad: transcurso de una filosofía biológica ajena a todo tiempo histórico, a la integración de la vida en el tiempo geológico y cosmológico}

A principios del siglo XIX, aproximadamente cincuenta años antes de publicarse El origen de las especies, el idealismo alemán, la corriente dominante del escenario filosófico coetáneo, ya había argumentado una concepción dinámico-evolutiva de la naturaleza. Georg W. F. Hegel (1770-1831) aportó con su dialéctica un sistema de pensamiento que comprendía lo real como un holístico proceso en constante desarrollo y superación, una progresión autorrecurrente donde cada movimiento sucesivo surge como resolución directa de las contradicciones inherentes al anterior. Con ello, en la concepción de la realidad, pasa a primer y decisivo plano lo histórico, el devenir social del ser humano en continuo progreso evolutivo mediante superación de las propias contradicciones y aprendizaje de los propios errores. Proceso análogo al de superar las limitaciones y necesidades derivadas de la supervivencia, operado por el enrolamiento acumulativo de mutaciones adaptadoras implícito en la selección natural.

En el pensamiento de Friedrich Nietzsche (1844-1900) se refleja la importancia desempeñada por la historia a partir de Hegel, e igualmente la propia influencia del evolucionismo de Darwin. Al concebir el Übermensch como el estadio superior de desarrollo humano, de algún modo Nietzsche contempla la historia como un proceso evolutivo de perfeccionamiento y mejora, mediante el cual el ser humano supera etapas anteriores marcadas por la debilidad y el acomplejamiento, hasta imponer su voluntad de poder y dominio sobre aquello que le rodea. Ahora bien, además Nietzsche rechaza la linealidad de la concepción tradicional de la historia, oponiéndole la circularidad propia de la doctrina del eterno retorno. Con ello, la historia se asimila a un astro en perpetua rotación sobre el eje del devenir, con lo cual los acontecimientos se repiten sin cesar, en un eterno retorno de lo mismo causado por la finitud del universo y el número limitado de sus elementos integrantes.

Gracias a la doctrina del eterno retorno de Nietzsche y a la teoría evolucionista de Darwin, la concepciones del tiempo y la historia subyacentes al creacionismo son objeto de una doble y pareja deconstrucción, filosófica y científica respectivamente. El fijismo y la atemporalidad característicos del pensamiento creacionista constituyen, para la sospecha nietzscheana, la máscara de la volun- 
tad de permanencia ontológica, el enmascaramiento del deseo de alcanzar un mundo inalterable. Es el falso consuelo frente a la angustia sentida por la inexorabilidad del cambio, del aithêr-logos ${ }^{13}$ señalado por Heráclito como constante cosmológica, espejismo disipado por la reincorporación del ser humano a la evolución biológica propiciada por la teoría evolucionista de Darwin. El universo afín a la hipótesis creacionista, sometido a la caracterización axial del Dios eterno y su correlato de atemporalidad, desconfía de una verdad en evolución o devenir llamada a dejar de serlo, aspira a la resistencia constante al paso del tiempo, y por ello, requiere la construcción intelectual de una verdad aquiescente con la permanencia. Nietzsche rechaza la equiparación entre verdad y permanencia, subraya la necesidad de invertir el platonismo de Parménides (circa 515-440 a.C.), vinculado a la idea de hypokeimenon o subiectum como médula del concepto «sustancia», y reivindica la reconciliación entre verdad y devenir. $\mathrm{O}$ expresándolo en términos darwinistas, entre verdad y evolución.

Contra la falsedad cognoscitiva de la hipótesis creacionista, la verdad biológica de la teoría evolucionista. La lucha por la supervivencia se convierte así en concepto clave de los categorismos de Nietzsche y Darwin, respectivos albaceas filosófico y científico de la herencia de Heráclito: el logos fuego, metamorfoseado filosóficamente en doctrina del eterno retorno y científicamente en teoría de la evolución. Con ellos, no hay sustancias que legalicen la permanencia del Ser, e incluso apenas si existe en su fugacidad el ente. Sólo existe realmente el agitado oleaje vital devenido en continuo e inexorable proceso evolutivo, sólo la corriente del devenir en eterno retorno, pues nada hay duradero ni estable, todo está sometido al heracliteano aithêr-logos fuego, la ley universal del devenir. El auténtico Ser es el flujo constante del tiempo cambiante. Y en el caso del ser humano, es Dasein deviniente, ser-en-el-mundo-en-devenir. Pero por nuestra condición de verdáboros, en palabras de Ortega, cual animales necesitados de mistificar lo real con verdades permanentes en la lucha cotidiana por la supervivencia, nuestro conocimiento falsea la realidad y transforma engañosamente la corriente del devenir en el ser permanente propio de las entidades conceptuales. Como las especies de seres vivos, en el tejido conceptual creacionista.

13 De verbo ad vérbum, «ardor racional». Pero, más allá de su estricta etimología, con el significado connotativo de «esencia intelectual pura» o "fulgor de intelecto celestial», por alusión a la quintaesencia divina como aliento vertebrador del universo, su elemento dinamizador, rector y explicativo. 
La sustancia atemporal inherente al concepto de especie viva manejado por la hipótesis creacionista, es una ficción existencialmente útil para escapar de la angustia derivada de aceptar un cosmos sometido al incierto devenir. Parafraseando a Martin Heidegger (1889-1976), es un producto de la voluntad de poder destinado a capturar la realidad del devenir, y subsumirla bajo concepto: «Imprimir en el devenir el carácter del ser —esto es la suprema voluntad de poder» ${ }^{14}$ Frente al espejismo creacionista del origen abrupto, la especie permanente y la ausencia de temporalidad, el conocimiento del eterno retorno permite comprender sin falseamiento al devenir como devenir y la teoría darwinista explicar el devenir de los fenómenos biológicos como evolución de las especies. Pero deconstruir la esencialidad atemporal implícita en el concepto de especie fija, conlleva consecuencias adicionales si se trata del Homo sapiens, particularmente en el ámbito de la Antropología.

La especie humana desprovista de esencia atemporal y reintegrada en paridad a una historia biológica sujeta a evolución, pierde la vinculación sobrenatural y regalía jerárquica de su anterior estatus en la naturaleza. Corolario lógico de su concepción evolucionista, Darwin acometió el estudio de la evolución humana en La descendencia del hombre y la selección sexual (1871). Al señalar en esta obra la incardinación plena y paritaria del ser humano en la naturaleza, su animalidad y su genealogía biológica procedente de los primates, desenmascaró su pretendida autonomía biológica y superioridad esencial. Si Nicolás Copérnico (1473-1543) había desplazado a la especie humana del centro del universo, Darwin lo desencumbró de su sedicente pedestal en la naturaleza, mostrándolo en su desnudez como el fruto copartícipe de los mismos principios rectores de la evolución biológica operantes para todo ser vivo.

Asimilar la concepción del tiempo subyacente a la teoría evolucionista permite a la Biología abandonar su autoculpable minoría de edad. De hecho, en tanto no se interioriza el auténtico alcance del potencial de crçnov como medio precipitante de cambios a través de la actualización de probabilidades ${ }^{15}$, se rehú-

14 Heidegger, 1994: p. 107.

15 La argumentación antievolucionista basada en la improbabilidad muestra una terca miopía cuando afirma la imposibilidad de que un proceso tan dependiente del azar, como el postulado por Darwin, sea el responsable de los organismos vivos hoy observados. Es como si un chimpancé mecanografiara Don Quijote tecleando al azar, o como si un vendaval construyera un Boeing 747 al arre- 
sa obstinadamente a aceptar que la evolución opere por combinación de la causalidad aleatoria producida con la deriva genética y la causalidad necesaria fruto de la selección natural. Por ello el creacionista adepto experimenta serias dificultades cognitivas para captar la evolución biológica, porque se aferra al provincianismo temporal de la inmediatez inherente al acto sobrenatural de creación.

La incomprensión de la profundidad del tiempo geológico requerido por la evolución de las especies constituye uno de los más pesantes lastres en la aceptación de la teoría de Darwin ${ }^{16}$. Incluso tratándose de los organismos más longevos, en un millón de años pueden sucederse decenas de miles de generaciones, y a menudo las especies perviven durante decenas o centenares de millones de años. Ello arroja un resultado de miles de millones de chances para la ocurrencia de mutaciones favorables, reclutadas por la selección natural y preservadas durante millares de generaciones, acumulándose los cambios exitosos de modo que la eficacia en la adaptación mejora según el rumbo favorecido por el entorno. La causalidad necesaria de la selección natural parte de la causalidad aleatoria de la variabilidad genética, pero trasciende su mera contingencia, al orientar el cambio evolutivo de la vida, a través del tiempo geológico, en la dirección de la supervivencia marcada por el éxito en la adaptación ambiental.

Sin embargo, evidentemente este proceso es incompatible con una Tierra moza, cuya longevidad oscile entre 4.000 y 8.000 primaveras. Por ello, las contradicciones más insuperables para el creacionismo proceden de la constatación de su inconsistencia con simples observaciones temporales directas, cuyo mejor prisma es el registro fósil. La concepción del tiempo subyacente al creacionismo queda reducida al absurdo ante la existencia palpable de la columna fósil, de una verificable acumulación de restos fósiles sucesivamente ancestrales vinculada a los respectivos estratos geológicos yuxtapuestos por orden cronológico. Esta noción de columna fósil permite tirar del hilo, convirtiendo el ovillo de la cronología creacionista en una telaraña de contradicciones insalvables. Afortunadamente para los antievolucionistas epígonos del creacionismo, nadie excepto sí

ciar sobre un montón de chatarra, afirman. Richard Dawkins ha refutado tan contundentemente este argumento de la improbabilidad contra la teoría evolucionista, que nos remitimos a su exposición en Dawkins, 1998.

16 Moreno, 2008: p. 57. 
mismos considera en serio sus argumentos, porque reputarlos rigurosos comporta inevitablemente una pléyade de paralogismos rayanos en lo cómico.

De ser históricamente cierto el tempo biológico creacionista implícito en una génesis abrupta, hallaríamos restos fósiles de todas las especies de seres vivos en todos los estratos geológicos cronológicamente considerados: justo lo contrario de los hechos observados, pues las especies ancestrales más remotas aparecen en los estratos más antiguos, mientras que las sucesivamente descendientes tienden a aparecer en los que son progresivamente más modernos. Si la historia natural procediera de un acto creativo de la totalidad de especies causado repentina y sobrenaturalmente en pocos días tras el Diluvio universal, deberíamos encontrar en todo el planeta restos de toda la gama de organismos vivos, y con mayor facilidad si se acepta el lapso de cuatro milenios: pero no los hallamos. El tiempo niega el creacionismo.

$\mathrm{Al}$ analizar el mito del arca de Noé y el posterior poblamiento de todo el planeta Tierra en apenas 4.000 años desde un mínimo punto geográfico de Asia, suele discutirse las dimensiones de la embarcación para albergar tan alto número de parejas, así como sus problemas de subsistencia durante semanas de confinamiento. Si bien esto, por si mismo, constituye una dificultad quizás definitivamente irresoluble, en realidad se trata de un problema menor. Considérese por ejemplo la distribución geográfica de las especies vivientes; resulta físicamente imposible generar la presente distribución de especies en 2.000 años $^{17}$. ¿Cómo supervinieron al Diluvio los peces de ríos y lagos, que por razones osmóticas no sobreviven en agua salada? ¿Cómo se distribuyeron por el mundo después dichos peces de aguas continentales? ¿Cómo ocuparon los seres vivos todos los hábitats del planeta en dos milenios, emigrando desde un nicho ecológico espacialmente reducido y sujeto a condiciones hiperrestrictivas, hasta optimizar su adaptación a una miríada de ecosistemas ni por asomo homogéneos e incluso a menudo incompatibles? Salvo hilarante recurso a una absurda cascada de hipótesis creadoras ad hoc, sencilla y llanamente, falta tiempo. El tiempo reniega el creacionismo.

17 Obviamente, según la hipótesis creacionista la distribución actual de las especies y la existente en tiempos de Cristo coinciden. Dado que $4.000-2.000=2.000$, eso significaría que la distribución actual de especies se produjo entre la creación postdiluvial de hace 4.000 años y la contemporaneidad con Cristo. Esto es, lo máximo en unos 2.000 años. 
Más aún. Admitida la población del planeta Tierra a partir únicamente de las parejas de animales liberadas del arca de Noé en el Monte Ararat, nos enfrentamos irremisiblemente a dos hipótesis alternativas, ambas acontecidas además en 2.000 años: aceptar una evolución vertiginosa que originó nuevos géneros, familias y órdenes a través de todo el planeta, o bien aceptar una extinción masiva, de manera que desde una distribución homogénea mundial de todas las especies, propia de una creación abrupta y generalizada, se pasó a la actual distribución ecológicamente localizada ${ }^{18}$. Por tanto, si se acepta por un lado el Diluvio y la travesía zoófila del arca de Noé como hechos ciertos e históricamente acaecidos, y por otro, se admite también la datación de la Tierra calculada por Usher en 4.000 años, reducidos a efectos de la presente discusión a 2.000, entonces explicar el escenario mostrado por la biota terráquea actual conduce a dos alternativas excluyentes: evolución trepidante o extinción masiva. La tragicomedia del pensamiento creacionista es su incompatibilidad con ambas. El tiempo requeteniega el creacionismo.

La historia natural afirma a Darwin, su evolución es revolución temporal.

\section{Del determinismo al indeterminismo: transcurso de la mecánica clásica newtoniana al paradigma evolutivo-relativista}

Todo cae. Esta locución de dos palabras resume en el fondo la mecánica clásica, pues Isaac Newton (1642-1727) explica el movimiento de los cuerpos celestes en su Principios matemáticos de filosofía natural (1687) con idénticos principios dinámicos explicativos de la caída de los cuerpos terrestres. La matemática newtoniana consigue unificar, mediante este «sistema del mundo», todo el universo bajo las mismas leyes. La órbita elíptica de los cuerpos celestes ${ }^{19}$ resulta de un movimiento inercial ${ }^{20}$ y de la fuerza de atracción del Sol, cuyo valor es directamente proporcional al producto de las masas e inversamente proporcional al

18 Aunque en este segundo caso, adicionalmente deberíamos encontrar los restos recientes de estas mismas especies a través de todo el mundo: pero no los hallamos en el registro fósil.

19 Primera ley de Kepler: los planetas se desplazan alrededor del Sol describiendo órbitas elípticas, estando el Sol situado en uno de los focos.

${ }^{20}$ Principio de inercia de Galileo. 
cuadrado de la distancia ${ }^{21}$. Por ello los planetas caen hacia el Sol y la Luna hacia la Tierra, igual que una de las dos manzanas más célebres de la historia ${ }^{22}$ cayó madura desde un árbol hasta la superficie terrestre. Ergo, todo cae.

A partir de finales del siglo XVIII, este cayente sistema del mundo newtoniano deja expedita a la comunidad científica la senda de algún tipo de cosmología basada en una concepción determinista de la realidad. Con sus Principia, Newton había infundido carne, sangre, alma y azufre al demonio liberado después por Pierre Simon Laplace (1749-1827) en el prefacio de su Ensayo filosófico sobre la probabilidad (1814), donde el marqués formuló las bases filosóficas del materialismo mecanicista más radicalmente partidario del determinismo. Laplace apela a una concatenación procesal determinista de estados físicos sucesivos para exponer su concepción cosmológica, describiendo el estado actual del universo como el efecto de su estado anterior, y simultáneamente, como causa del siguiente. Por ello, afirma, si una inteligencia pudiera analizar y calcular los datos relativos a todas las fuerzas actuantes en la naturaleza y la posición respectiva de sus entes integrantes, podría predecir con éxito su movimiento con una fórmula, y por tanto, cualquier estado del universo, pues «nada le resultaría incierto, y tanto el futuro como el pasado estarían presentes ante sus ojos» ${ }^{23}$, exacerbando el determinismo ínsito en la mecánica clásica hasta proyectarlo en todo fenómeno natural, y acuñando el denominado determinismo causal, materialismo determinista o mecanicismo.

Ángel expulsado del Olimpo del saber, el demonio de Laplace ya no mora en el paradigma científico contemporáneo. Sus dos principales exorcistas fueron Heisenberg en Física y Darwin en Biología.

${ }^{21}$ Tercera ley de Kepler: el cuadrado del período orbital de cualquier planeta es directamente proporcional al cubo de la distancia media con el Sol. Anecdóticamente, en los escritos de Kepler se aprecia cómo, aun siendo consciente de que sus leyes explicaban el movimiento planetario, no entendía exactamente las razones de su comportamiento. Fue Newton quien extrajo de la obra de Kepler la formulación matemática precisa de sus leyes empíricas, relacionándolas con sus propios descubrimientos, hasta conferirles sentido físico y formular la ley de la gravitación universal.

22 Es decir, la adánica y la newtoniana. Curiosamente, ambas manzanas ocupan un lugar histórico memorable en la simbología empleada por la religión y la ciencia para difundir sus respectivos discursos; el mito sobre la causa originaria del problema ético suscitado por la elección entre el bien y el mal, y la explicación empírico-racional sobre la causa de la caída de los graves.

${ }^{23}$ Laplace, 1985: p. 25. 
Werner Heisenberg (1901-1976) formuló la llamada relación de indeterminación o principio de incertidumbre en 1927, para argumentar su mecánica matricial, cuyo planteamiento diverge por completo de la mecánica clásica. No pretende el análisis matemático de cada paso en la cadena evolutiva del estado físico, como defendía el marqués de Laplace, sino que atiende a los estados inicial y final, desentendiéndose de los intermedios excepto si son decisivos para todo el proceso. Con esta nueva filosofía física, Heisenberg agrupó la información en cuadros de doble entrada, obteniendo un resultado matemático sorprendente: la multiplicación matricial no satisface la propiedad conmutativa, pues el orden de sus factores sí altera el producto final. En consecuencia, toda asociación entre magnitudes físicas y matrices ha de tener su correlato matemático específico. Este resultado le llevó a formular el principio de incertidumbre ${ }^{24}$, por el cual, es imposible la determinación simultánea de la posición y la velocidad de una partícula atómica con un grado de precisión arbitraria ${ }^{25}$. A partir de ahí, demostró que el producto de ambas imprecisiones es igual o superior a un valor dado — constante de Planck, $\mathrm{h}=10^{-27}$ —, justificando la imposibilidad de conocer, a nivel subatómico, la situación de un cierto estado físico en un instante dado, con precisión suficiente para poder predecir la situación del mismo en un instante inmediatamente posterior. Ello excluye el demonio laplaceano, al descartar que el determinismo gobierne la realidad subatómica, y además consagra la inexactitud como propiedad consustancial a su conocimiento. Por tanto, en el dominio de la física de partículas, propio de la mecánica cuántica, las leyes de ciencia sólo logran una formulación estadística, no universalmente necesaria, y de ahí que la comunidad científica en general considere a la mecánica cuántica una acertada teoría indeterminista en la cual el azar desempeña alguna función, aunque limitada.

Algo similar ocurre con la teoría del caos, al describir ciertos comportamientos impredecibles de los llamados sistemas dinámicos —estables, inestables y caóticos-, pues muestra la imposibilidad de formular predicciones exactas a partir de cierto número de estados físicos sucesivos. La tesis ultradeterminista de Lapla-

${ }^{24}$ Heisenberg, 1969 y 1996.

25 «Puede señalarse muy precisamente la posición, pero entonces la influencia de la observación imposibilita hasta cierto grado el conocimiento de la velocidad; e inversamente, se desvanece el conocimiento de la posición al conocer precisamente la velocidad; en forma tal, que la constante de Planck constituye un coto inferior del producto de ambas imprecisiones». Heisenberg, 1969: p. 39. 
ce sólo muestra buena adecuación con sistemas estables, tendentes durante el tiempo a un punto u órbita denominado atractor o sumidero; pues, dadas determinadas condiciones iniciales fijas, conociéndose sus ecuaciones características, puede predecirse exactamente su evolución temporal. Su adecuación ya es considerablemente menor para los sistemas inestables, que muestran gran dependencia de las condiciones iniciales y tienden a escapar de los atractores con el tiempo, lo cual dificulta predecir su evolución. Pero los sistemas caóticos - la atmósfera terrestre, los fluidos o el crecimiento de población-, sometidos a fuerzas que los atraen y a la vez alejan del atractor, son definitivamente incompatibles con el determinismo causal laplaceano, pues una mínima diferencia en las condiciones iniciales provoca una evolución totalmente distinta e impredecible del sistema. Así se explica que las predicciones climatológicas rara vez sean exactas más allá de los tres o cuatro días, pues aun disponiendo de potentes ordenadores, parejos a la mente omniscia añorada por Laplace, y además de un modelo matemático preciso para describir el clima atmosférico, al carecer de parámetros exactos que fijen las condiciones iniciales — toda medición comporta errores, por mínimos que sean-, el modelo diverge de la realidad considerablemente con el transcurso del tiempo, truncando así la evolución del proceso cualquier posibilidad de éxito predictivo.

Similar efecto exorcista contra la influencia producida por el determinismo de Laplace en Física, generó en Biología la teoría de la evolución de las especies por selección natural de Darwin, pues supuso el principio del acceso del azar a la ciencia biológica. En un contexto de investigación cuya metodología científica se basaba en los principios matemáticos, las leyes de la Física y el determinismo causal, el pensamiento darwinista, además de ciertos conceptos clave específicos de las ciencias naturales, introdujo importantemente las nociones de probabilidad, azar y singularidad.

Así, una de las aportaciones más genuinas del pensamiento darwinista estriba precisamente en una creativa combinación de causalidad estocástica y necesaria. Pues, como intuyó Darwin, fundamentó Mendel y confirmó posteriormente la Genética, una combinación de causalidad azarosa o variabilidad y causalidad necesaria o selección natural, provoca en última instancia la evolución de las especies mediante la producción de información genética nueva, toda vez que se activa una mutación genética ( azar $_{1}$ ), oferente de ventaja adaptativa en un entorno cambiante e impredecible $\left(\operatorname{azar}_{2}\right)$, para recibir luego los indivi- 
duos favorecidos y su descendencia el beneplácito de la selección natural (necesidad). Esta combinación causal de azar y selección natural para explicar los fenómenos biológicos, propia de la teoría evolucionista de Darwin, otorga a la causalidad estocástica un estatus epistemológico del que antaño carecía en ciencia, pues hasta entonces sólo la causalidad necesaria resultaba coherente con teorías como la mecánica clásica de Newton, afines a una ciencia basada en el determinismo de lo real.

Se aprecia así cómo, tras la mecánica matricial de Heisenberg y la teoría de la evolución por variabilidad y selección natural de Darwin, el concepto de azar constituye una categoría clave para la idea de ciencia posterior al determinismo laplaceano. Hasta el extremo que Jacques Monod (1910-1976) considera al azar como la noción central de la Biología moderna, en dos sentidos. En primer lugar, porque el mismo mecanismo subyacente a la evolución biológica — selección natural entendida como descendencia con modificación-, depende en gran medida de mutaciones casuales en la transmisión intergeneracional del genoma, producidas básicamente por errores en la transcripción de la información genética ocasionados al azar, y cuya conversión en ventaja adaptativa potencial suele deberse a una combinación, también fortuita, de duplicación aleatoria y mutación ${ }^{26}$. Y en segundo, porque las mismas consecuencias funcionales de la mutación ya producida por azar dependen de una coincidencia con las condiciones ambientales, que han de favorecer la perpetuación de esta mutación, por cuanto pueda proporcionar una ventaja adaptativa susceptible de selección natural.

Por ello, Monod insiste en la importancia del presupuesto aleatorio a partir del cual interactúa la selección natural, es decir, la deriva genética, pues ambas fuerzas evolutivas son los cofactores responsables de la evolución. La variabilidad de genes promovida en la deriva genética, consiste en un cambio aleatorio en la

26 «El mecanismo de la replicación no podría tampoco, sin violar las leyes de la física, escapar a toda perturbación, a todo accidente. Al menos, algunas de estas perturbaciones entrañarán modificaciones más o menos discretas de ciertos elementos de secuencia. Errores de transcripción que, en virtud de la fidelidad ciega del mecanismo, serán, junto a otras perturbaciones, automáticamente retranscritos. Serán fielmente traducidos en una alteración de la secuencia de los aminoácidos en el polipéptido correspondiente al segmento de ADN en el que se producirá la mutación. Mas hasta que este polipéptido parcialmente nuevo se repliegue sobre si mismo no se revelará la «significación funcional» de la mutación». Monod, 1984: p. 124. Cursiva en el original. 
frecuencia de alelos transmitidos de una generación a otra, y constituye un efecto estocástico que emerge del rol de muestreo aleatorio desempeñado por la reproducción. Esta causalidad estocástica implícita en la deriva genética, tras su filtrado por la causalidad necesaria implícita en la selección natural, impulsa al final la evolución de las especies.

El pionero francés de la Genética Molecular, coincidiendo en nuestra perspectiva sobre la importancia que el azar adquiere en la Biología moderna tras la obra de Darwin, subraya que esas alteraciones nutrientes de la deriva genética son accidentales, tienen lugar aleatoriamente. $\mathrm{Y}$ al constituir la única fuente posible de modificaciones del código genético, depositario exclusivo de las estructuras hereditarias, entonces el azar se halla necesariamente implicado en el origen causal de toda creación biótica. Por ello Monod concluye en que la libertad absoluta, aunque ciega, constituida por el puro azar, está «en la raíz misma del prodigioso edificio de la evolución: esta noción central de la biología moderna no es ya hoy en día una hipótesis [...] [sino la] única compatible con los hechos de observación y de experiencia» ${ }^{27}$, sin que el conocimiento disponible en su época aconseje considerarla refutada. En efecto, la Genética actual ha confirmado su predicción, demostrando por doquier la fuerte correlación existente entre la evolución de las especies y una sucesión aleatoria de coyunturas tejidas estocásticamente mediante la intersección de coincidencias absolutas, en las cuales resulta evidente el papel crucial desempeñado por el azar. Pero en el caso de la Biología, el método de investigación u observación no afecta ni en lo más mínimo al resultado cognitivo, como en cambio sí sucede en Física con el principio de incertidumbre actuante en la mecánica cuántica.

El último intento teórico serio de poner en tela de juicio la función desempeñada por el azar en la explicación causal de los fenómenos biológicos, señalada por la teoría evolucionista de Darwin, procede de la idea de complejidad específica propuesta por William Dembski, tal vez uno de los principales defensores y líderes intelectuales del movimiento para el diseño inteligente. Veamos qué discusión generaría confrontar las objeciones señaladas por la teoría de la información compleja específica de Dembski a la causalidad combinada de azar y selección natural subyacente a la teoría evolucionista de Darwin.

${ }^{27}$ Monod, 1984: p. 125. 
Dembski define la complejidad específica como todo suceso, dotado de un patrón reconocible, con una probabilidad de ocurrencia espontánea inferior a $10^{-150}\left(\mathrm{CE}=\mathrm{p}<10^{-150}\right)^{28}$, bajo cuyo umbral puede asumirse que no fue producido por azar ni causa natural, sino diseñado o producido por causalidad inteligente. Su complemento teórico es el llamado filtro explicativo, según el cual, un suceso sólo puede ocurrir por tres tipos de causas: $\left(1 .^{a}\right)$ Necesidad, asociada con una probabilidad alta o regularidad; (2. ${ }^{a}$ ) Azar, asociada con una probabilidad intermedia; y, (3. ${ }^{\text {a })}$ Diseño, la aludida probabilidad inferior a $10^{-150}$. Aplicando la estrategia argumentativa del filtro explicativo, Dembski sostiene que, si pueden descartarse las causalidades necesaria y azarosa, deberá ser admitida la causalidad por diseño inteligente.

Las objeciones que pueden plantearse al concepto de complejidad específica así definido, son múltiples. En primer lugar, Dembski no acota nunca el rango matemático abarcado por las indicadas nociones de probabilidad «alta»e «intermedia», cuestión particularmente problemática en este último caso. Pues desde una probabilidad alta — digamos entre 0,75 y 0,99 respecto de la unidad-, hasta el $10^{-150}$ usado para marcar el límite de ínfima probabilidad implícito en la causalidad por diseño, existe un universo de discurso amplísimo. ¿Qué entendemos por probabilidad intermedia? ¿0,3?, ¿0,333?, o ¿quizás 0,3333333333? Hasta llegar a los 150 decimales definitorios, según Dembski, de la causalidad por diseño, resta todavía un largo e indefinido abanico de posibilidades. Pronto se advierte que este planteamiento carece del mínimo rigor, para considerarlo fundamento sólido de la inferencia del diseño. Incluso tratándose de quien fue apodado con el bombástico apelativo de «el Newton de la teoría de la información", la presunta base teórico-formal de la hipótesis del diseño inteligente.

Pero además, al aplicar el susodicho filtro explicativo, conducido por su pasión vehemente de justificar la causalidad por diseño inteligente cual mecanismo explicativo del surgimiento de las especies de seres vivos, Dembski prescinde olímpicamente del método científico. No completa una verificación por casos de las hipótesis alternativas posibles y las somete después todas a idéntico análisis, para extraer conclusiones. Más bien discute sólo sobre dos de las tres hipótesis predefinidas, formula su argumentación claramente tendenciosa contra ambas, y

${ }^{28}$ Dembski, 1998: pp. 209-14; y también Dembski, 1999: pp. 166 y ss. 
tras descartarlas, concluye aceptando la tercera sin cribarla por el mismo análisis. Es decir, estamos ante un filtro que no filtra una de las hipótesis, ante un método probatorio de descarte por casos, pero aplicado de modo incompleto. Y por tanto no resulta explicativo, sino antes bien clamorosamente petitorio de principio. $\mathrm{O}$ meramente supresor ${ }^{29}$, ya que está concebido para eliminar las hipótesis de forma secuencial: primero la regularidad y después la aleatoriedad, para admitir el diseño como opción por defecto. Este planteamiento, propio de una ciencia formal como la Lógica o la Matemática pero impropio de una ciencia empírica como la Biología, es incompatible con un modelo de inferencia científica legítima, pues la asimetría en el método analítico de las hipótesis discutidas, no garantiza excluir las conclusiones falsas.

Por si fuera poco, este "filtro explicativo», noción complementaria de la idea de complejidad específica, adolece además de una selección flagrantemente incompleta de hipótesis. Cuando, en su discusión favorable a la causalidad por diseño inteligente como mecanismo descriptor de los fenómenos estudiados por la Biología, Dembski aplica la maniobra de filtrado a nivel microbiológico para descartar la causalidad necesaria ${ }^{30}$, representada por la selección natural en el tejido conceptual de la teoría evolucionista, omite una hipótesis crucial: la posible combinación entre las alternativas definidas. Pues como antes se apuntó, la combinación de azar — variabilidad—y necesidad — selección natural—, sí puede generar y genera información, material genético nuevo y susceptible de provocar la transformación evolutiva de las especies, al permitir la activación de una mutación genética (causalidad aleatoria ${ }_{1}$ ) que ofrece ventaja adaptativa en un entorno cambiante (causalidad aleatoria ${ }_{2}$ ), de tal modo que después los individuos beneficiados y su descendencia puedan ser favorecidos por selección natural (causalidad necesaria).

Mutación genética aleatoria. Este es precisamente el proceso señalado por la síntesis evolutiva moderna como responsable último de la evolución. Las mutaciones no adaptativas o «neutrales», son irrelevantes para la acción inhe-

29 Wilkins y Elsberry, 2001.

30 Para Dembski, como es sabido pero entendemos oportuno recordar ahora, los organismos son complejamente específicos en el ámbito microbiológico, es decir, están causados por diseño inteligente —única alternativa capaz de generar información genética nueva- y no por azar o necesidad. 
rente a la fuerza evolutiva de la selección natural, pero no aquellas que proporcionan ventaja adaptativa. Gracias a la reproducción sexual, estas mutaciones ventajosas producen individuos y especies tendentes a superar el test de la selección natural, que impone la inexorable ley de su causalidad necesaria. Así, los procesos genéticos involucrados en la evolución tienden a acumular los cambios en el ADN positivos — adaptativos—, y a descartar los negativos — no adaptativos-, razón por la cual, con el transcurso sucesivo de las generaciones y en términos de tiempo geológico, el respectivo genoma de cada especie evoluciona. A la postre este proceso, incólume incluso admitiendo ex hypothesi un concepto vacío o sin referente empírico como la complejidad específica de Dembski, deviene el verdadero agente responsable del incremento de la naturaleza en complejidad o especificidad, y su verificación reiterada por la comunidad científica, dicho sin circunloquios, convierte en superfluo el recurso a una presunta causalidad sobrenatural producida por un diseñador omnipotente. Con ello, las objeciones formuladas desde la inferencia del diseño contra la combinación causal de azar y selección natural decaen, y la conclusión se sigue por sí misma.

Sic, al estudiar la naturaleza, el evolucionismo de Darwin reconcilia el azar imprevisible y una ciencia no determinista. La casualidad deviene causalidad. El último guiño científico del maestro de maestros en Biología.

\section{Bibliografía}

Alonso, C., 1999. Tras la evolución. Panorama histórico de las teorías evolucionistas; Pamplona, Universidad de Navarra.

DAWKINS, R., 1998. Escalando el monte improbable; Barcelona, Tusquets.

Dembski, W., 1998. The Design Inference; New York, Cambridge University Press.

- 1999. Intelligent Design. The Bridge Between Sciencie and Theology; Madison, InterVarsity Press.

Diels, H., 1968. Los presocráticos y sus fragmentos: desde los milesios hasta los sofistas del siglo V; Buenos Aires, Juárez. Traducción de Alfredo Llanos.

EGGERS, C., 1986. Los filósofos presocráticos; Madrid, Gredos.

Gardner, M., 1995. El escarabajo sagrado; Barcelona, Salvat. 
Heidegger, M., 1994. Quién es el Zaratustra de Nietzsche, Conferencias y artículos; Barcelona, Odós.

HeIsenberG, W., 1969. La imagen de la naturaleza en la Física actual; Barcelona, Seix Barral.

Huxley, J. y Kettlewell, H. 1965. Charles Darwin and his world; London, Thames and Hudson. Traducción española: Darwin, Barcelona: Salvat, 1987.

LAPLACE, P., 1985. Ensayo filosófico sobre las probabilidades; Madrid, Alianza.

Monod, J., 1984. El azar y la necesidad. Ensayo sobre la filosofía natural de la Biología moderna; Barcelona, Tusquets.

Moreno, J., 2008. Los retos actuales del darwinismo. ¿Una teoría en crisis?; Madrid, Síntesis.

NeEDHAM, J. et al., 1952. "Ancient and Medieval Chinese Thought on Evolution»; Bulletin Nature, Institute of Sciences of India, 7: Symposium on Organic Evolution, 1.

- 1954. Science and Civilisation in China; Cambridge, Cambridge University Press.

Pelayo, F., 2001. Darwin. De la creación a la evolución; Tres Cantos, Nivola.

WilKINS, J. y ELSBERRY, W., 2001. «The Advantages of Theft over Toil: The Design Inference and Arguing from Ignorance»; Biology and Philosophy, 16: 711-24.

Recibido: 30/09/2009

Revisado: 10/10/2009 
